\title{
COMPUTATIONAL MODELING OF RTM AND LRTM PROCESSES APPLIED TO COMPLEX GEOMETRIES
}

\begin{abstract}
J. da S. Porto ${ }^{\mathrm{a}}$,
M. Letzow ${ }^{a}$,

E. D. dos Santos ${ }^{\mathrm{a}}$,

S. C. Amico ${ }^{b}$,

J. A. Souza ${ }^{a}$,

and L. A. Isoldi ${ }^{a}$

${ }^{a}$ Universidade Federal do Rio Grande

Escola de Engenharia (EE)

Av. Itália km 8, Rio Grande-RS, Brasil

${ }^{\mathrm{b}}$ Universidade Federal do Rio Grande do Sul

Departamento de Materiais

liercioisoldi@furg.br

\section{ABSTRACT}

Light Resin Transfer Molding (LRTM) is a variation of the conventional manufacturing process known as Resin Transfer Molding (RTM). In general terms, these manufacturing processes consist of a closed mould with a preplaced fibrous preform through which a polymeric resin is injected, filling the mold completely, producing parts with complex geometries (in general) and good finish. Those processes differ, among other aspects, in the way that injection occurs. In the RTM process the resin is injected through discrete points whereas in LRTM it is injected into an empty channel (with no porous medium) which surrounds the entire mold perimeter. There are several numerical studies involving the RTM process but LRTM has not been explored enough by the scientific community. Based on that, this work proposes a numerical model developed in the FLUENT package to study the resin flow behavior in the LRTM process. Darcy's law and Volume of Fluid method (VOF) are used to treat the interaction between air and resin during the flow in the porous medium, i.e. the mold filling problem. Moreover, two three-dimensional geometries were numerically simulated considering the RTM and LRTM processes. It was possible to note the huge differences about resin flow behavior and filling time between these processes to manufacture the same parts.
\end{abstract}

Keywords: LRTM, RTM, Computational Modeling, Numerical Simulation

\section{NOMENCLATURE}

$\begin{array}{cl}f & \text { volume fraction } \\ \vec{F} & \text { force term, } \mathrm{N} / \mathrm{m}^{3} \\ \vec{g} & \text { gravity acceleration, } \mathrm{m} / \mathrm{s}^{2} \\ K & \text { permeability, } \mathrm{m}^{2} \\ p & \text { pressure, } \mathrm{Pa} \\ \vec{v} & \text { velocity vector, } \mathrm{m} / \mathrm{s} \\ t & \text { time, } \mathrm{s}\end{array}$

\section{Greek symbols}

$\begin{array}{ll}\rho & \text { density, } \mathrm{kg} / \mathrm{m}^{3} \\ \mu & \text { resin viscosity, Pa s } \\ \varepsilon & \text { porosity } \\ = & \text { stress tensor, } \mathrm{Pa} \\ \tau & \\ \rho & \text { density, } \mathrm{kg} / \mathrm{m}^{3} \\ \mu & \text { resin viscosity, Pa s } \\ \varepsilon & \text { porosity } \\ = & \text { stress tensor, } \mathrm{Pa} \\ \tau & \end{array}$

\section{INTRODUCTION}

Light Resin Transfer Molding (LRTM) is a variation of the conventional composite manufacturing process known as Resin Transfer Molding (RTM). In both processes, the polymeric resin is injected into a closed mold which has been previously filled with a dry fibrous reinforcement. Figure 1 shows a scheme of the RTM processes.

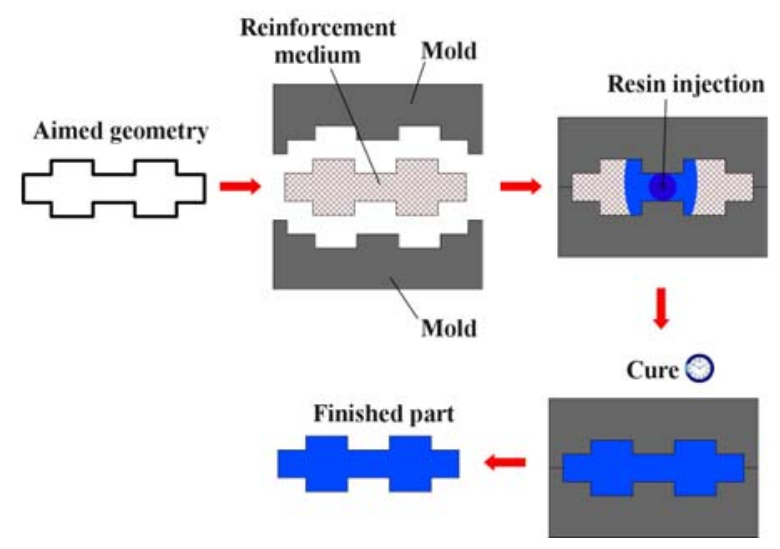

Figure 1. Scheme of RTM processes.

With regard to resin injection, RTM uses a few discrete points while in LRTM the resin is injected by means of a cavity (with no fibrous reinforcement) which circumvents the mold.

One of the greatest difficulties in applying RTM and LRTM processes is related to mold filling, i.e. to guarantee that the fibrous reinforcement is completely impregnated by the resin inside the mold. Besides, in order to manufacture quality composites through RTM, it is necessary to minimize the void content inside them. The presence of voids is harmful to the mechanical properties of the parts, such as the decreasing of shear, compression, impact and fatigue 
strength. The appearance of voids is related to injection pressure, outlet pressure, resin properties and the characteristics of the fibrous reinforcement such as fiber type and fiber orientation (Jinlian et al. 2004).

Through computational modeling it is possible to predict the resin flow behavior inside the mold. According to Shojaei (2006), the use of numerical simulation for RTM can help the determination of the flow evolution, and the location of the flow front and possible regions of void formation, hence enabling an efficient mold design. According to Shin et al. (2006), the prediction of flow advance is very useful to reduce the processing time and to improve the final product properties. Thus, numerical simulation appears as an important tool in the mold design in the RTM and LRTM manufacturing process.

In the present work, three-dimensional cases of RTM and LRTM processes were simulated. Initially, verification and validation of the computational model used for the RTM process was carried out. Afterwards, a comparison between the RTM and LRTM processes are carried out in two geometries: a Spherical Calotte and a Perforated Spherical Calotte.

\section{COMPUTATIONAL MODELING OF THE RTM PROCESSES}

In RTM, as mentioned before, the mold is filled with a fibrous reinforcement through which the resin is forced to flow. The reinforcement can be considered a porous medium and modeled with Darcy's Law, which correlates the pressure field with the velocity field inside this medium, expressed by:

$$
\vec{v}=-\frac{K}{\mu} \nabla p
$$

where $\vec{v}$ is the velocity vector $[\mathrm{m} / \mathrm{s}], K$ is the permeability $\left[\mathrm{m}^{2}\right], \mu$ is the viscosity of the resin [Pa.s] and $p$ is the pressure $[\mathrm{Pa}]$.

To solve RTM and LRTM problems with the FLUENT software, which is based on the Finite Volume Method (FVM), the Volume of Fluid (VOF) model has been used. The VOF model, proposed by Hirt and Nichols (1981), solves the fluid dynamic and heat transfer of two or more immiscible fluids. Through VOF, it is possible to identify the position of the interface among different phases of fluid. In addition, the fluid phases are well separate and the volume of a phase cannot be occupied by another one.

Considering the RTM and LRTM problems with two-phases (air/resin), the volume fraction concept $(f)$ is applied to represent the phases inside a cell (element). So, when $f=0$, the cell is fully filled with air. If $f=1$, the cell is fully filled with resin, and, for a range of $0<f<1$, it has both phases.
Only one set of equations for mass conservation and momentum is solved for the resin/air mixture. The continuity equation for the mixture is given by:

$$
\frac{\partial \rho}{\partial t}+\nabla \cdot(\rho \vec{v})=0
$$

where $\rho$ is the density $\left[\mathrm{kg} / \mathrm{m}^{3}\right]$ and $t$ is the time [s].

The momentum equation solved in the whole computational domain can be written as:

$$
\frac{\partial}{\partial t}(\rho \vec{v})+\nabla(\rho \overrightarrow{v v})=-\nabla p+\nabla \cdot(\overline{\bar{\tau}})+\rho \vec{g}+\vec{F}
$$

being $\vec{g}$ the gravity acceleration $\left[\mathrm{m} / \mathrm{s}^{2}\right], \bar{\tau}$ the stress tensor [Pa] and $\vec{F}$ the force per unit volume $\left[\mathrm{N} / \mathrm{m}^{3}\right]$ acting on the fluid.

In the present formulation, the porous medium effect is included in the model by inserting a resistive force to the flow in the momentum equation, Eq. (3). So, considering Eq. (1), it is possible to equate the term $\vec{F}$ in Eq. (3) as follows:

$$
\vec{F}=\nabla p=-\frac{\mu}{K} \vec{v}
$$

Besides, in each computational domain cell, the advective transport of the volume fraction $f$ is described by:

$$
\frac{\partial(f)}{\partial t}+\nabla \cdot(f \vec{v})=0
$$

With the definition of the volume fraction, the density and viscosity in each computer domain cell can be calculated by (Srinivasan et al., 2011):

$$
\begin{aligned}
& \rho=f \rho+(1-f) \rho \\
& \mu=f \mu+(1-f) \mu
\end{aligned}
$$

The computational modeling of the RTM process in both two-dimensional and threedimensional geometries has already been validated in previous studies. It was shown in Ribeiro et al. (2007) that it is possible to model and simulate the RTM process by using the FLUENT software. Two cases were studied: rectilinear and radial advance of the flow front line. In both cases, the results agreed well with the analytical ones.

Numerical RTM studies applied to multi-layers problems were presented in Oliveira (2010). Validation of the numerical solutions performed using the FLUENT software was obtained through comparison with experimental results. Moreover, considering three-dimensional problems with 
complex geometries, verification of the numerical model was also done by comparing its results with the solution obtained in a dedicated (RTM injection problems) software called PAM-RTM.

Another verification/validation of this numerical model was presented in Isoldi et al. (2012) who analyzed 2-D geometries and compared the numerical solutions with experimental and analytical results, and also 3D geometries which were verified comparing the numerical solution with those obtained with PAM-RTM software, showing excellent agreement among the results.

\section{RESULTS}

As already mentioned, initially the verification and validation of the computational model described above were performed. After that two complex geometries were numerically simulated comparing the behavior of the RTM and LRTM processes.

\section{A. Verification and Validation of the Computational Modeling}

In this geometry, the resin is injected in a threedimensional mold, comprised of an entry nozzle (with no fibrous reinforcement) and the mold cavity itself (a region with a fibrous reinforcement), as shown in Fig. 2. For this geometry, two different situations were analyzed: either ignoring the entry nozzle or taking the nozzle into account. For the former, only the mold was discretized by using a tetrahedral mesh with 13304 elements. The resin and fibrous reinforcement properties, as well as the continuous injection pressure are depicted in Table 1.
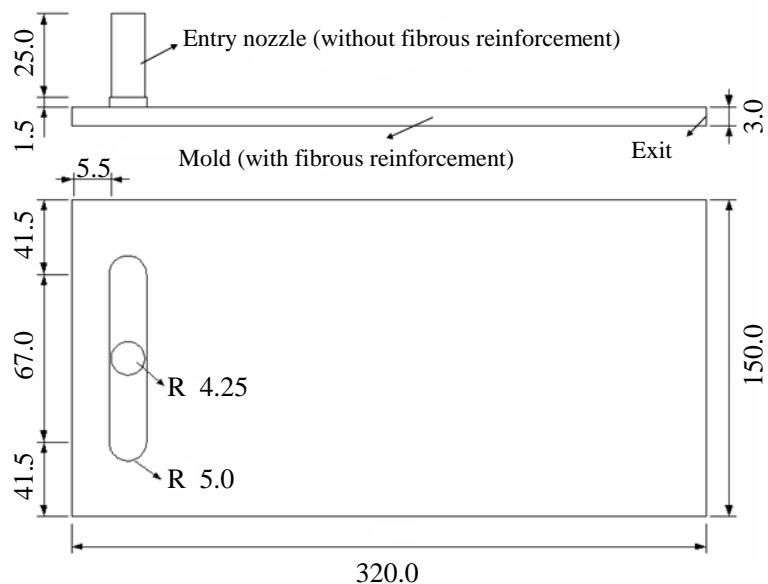

Figure 2. Three-dimensional mold used in the verification/validation (in $\mathrm{mm}$ ).

Figure 3 shows the advance of the flow front as a function of the injection time using the two numerical methodologies adopted here: FLUENT and PAM-RTM, which are based on FVM and FEM, respectively. It is possible to notice that the obtained results show good agreement.
Table 1. Fluid properties and injection pressure of the three-dimensional simulation.

\begin{tabular}{cccccc}
\hline \hline Case & $\rho$ & $\mu$ & $\varepsilon$ & $K$ & $p$ \\
& $\left(\mathrm{~kg} / \mathrm{m}^{3}\right)$ & $\left(\times 10^{-2} \mathrm{~Pa} . \mathrm{s}\right)$ & $\left(\times 10^{-2}\right)$ & $\left(\times 10^{-10} \mathrm{~m}^{2}\right)$ & $\left(\times 10^{5} \mathrm{~Pa}\right)$ \\
\hline 1 & 920.00 & 6.50 & 65.40 & 1.74 & 0.35 \\
2 & 920.00 & 7.10 & 66.80 & 2.41 & 0.60 \\
\hline \hline
\end{tabular}

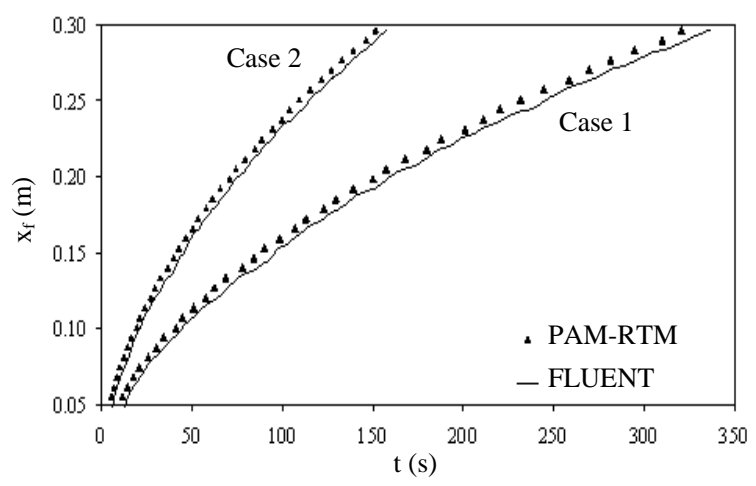

Figure 3. Simulation without the entry nozzle Verification.

For the second validation, the injection nozzle was taken into account (see Fig. 2) and the geometry was discretized using 29224 hexahedral elements. For these simulations, the properties are also those presented in Table. 1 with the exception of the injection pressure used in each case. Since the injection pressure was not constant, it was necessary to define an equation representing its variation as a function of the time. For that, the experimental data reported by Schmidt et al. (2009) was used to find a polynomial adjustment curve for the injection pressure (in $\mathrm{Pa}$ ) as follows:

$$
p=C_{0}+C_{1} t+C_{2} t^{2}+C_{3} t^{3}+C_{4} t^{4}+C_{5} t^{5}+C_{6} t^{6}+C_{7} t^{7}
$$

The coefficients of Eq. (8) are presented in Tables. 2 and 3 showing that, in Cases 1 and 2, after $57.00 \mathrm{~s}$ and $125.00 \mathrm{~s}$, respectively, the injection pressure approaches a constant value (Tab. 3).

\begin{tabular}{ccc}
\multicolumn{4}{c}{ Table 2. Coefficients of Eq. (8) } & Part 1. \\
\hline \hline$c_{\mathrm{n}}$ & $\begin{array}{c}\text { Case } 1 \\
(t \leq 57.00 \mathrm{~s})\end{array}$ & $\begin{array}{c}\text { Case } 2 \\
(t \leq 125.00 \mathrm{~s})\end{array}$ \\
\hline$c_{0}$ & 6339.50 & 3891.80 \\
$c_{1}$ & 1800.20 & 2720.10 \\
$c_{2}$ & $-597.16 \times 10^{-1}$ & $-650.88 \times 10^{-1}$ \\
$c_{3}$ & $108.30 \times 10^{-2}$ & $583.34 \times 10^{-3}$ \\
$c_{4}$ & $104.66 \times 10^{-4}$ & $527.85 \times 10^{-5}$ \\
$c_{5}$ & $418.91 \times 10^{-5}$ & $-156.33 \times 10^{-6}$ \\
$c_{6}$ & 0.00 & $119.13 \times 10^{-8}$ \\
$c_{7}$ & 0.00 & $-308.96 \times 10^{-11}$ \\
\hline \hline
\end{tabular}


Table 3. Coefficients of Eq. (8) - Part 2.

\begin{tabular}{ccc}
\hline \hline$c_{\mathrm{n}}$ & $\begin{array}{c}\text { Case 1 } \\
(t>57.00 \mathrm{~s})\end{array}$ & $\begin{array}{c}\text { Case 2 } \\
(t>125.00 \mathrm{~s})\end{array}$ \\
\hline$c_{0}$ & 30200.00 & 55500.00 \\
\hline \hline
\end{tabular}

The numerical results obtained in this work with FLUENT are compared with the experimental findings of Schmidt et al. (2009). Figure 4 shows the resin flow front as a function of time for the two studied cases and here again good agreement between numerical and experimental results was found. More information about the experimental procedures and the results can be found in Schmidt et al. (2009).

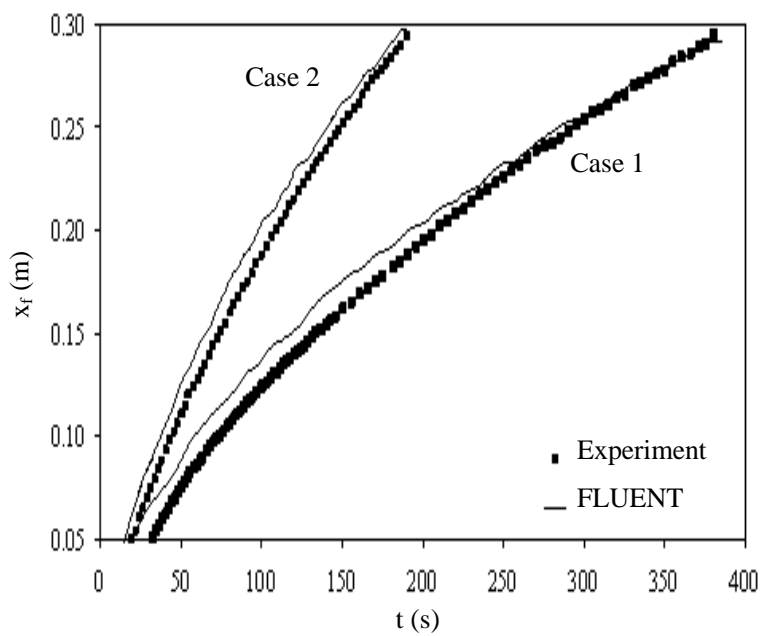

Figure 4. Simulation with the entry nozzle Validation.

In general, Figs. 3 and 4 indicate that the computer model developed in the FLUENT software is able to simulate the RTM process. Since analytical, numerical or experimental results for the LRTM process could not be found in the literature, the verification/validation carried out for RTM was also considered suitable for LRTM. This hypothesis is justified considering that the sole difference between these processes is the way that the resin is injected in the mold. It is worth to emphasize that an analogous verification procedure was considered in Porto et al. (2011).

\section{B. Spherical Calotte and Perforated Spherical Calotte}

The Spherical Calotte and Perforated Spherical Calotte studied geometries have the same dimensions. However, there are differences in the computational geometric domain for the two processes (RTM or LRTM). For RTM, Fig. 5 shows the geometry for the spherical calotte and Fig. 6 exhibits the domain for the spherical calotte with a perforated mold.



Figure 5. Spherical calotte geometry: RTM process (in $\mathrm{mm}$ ).
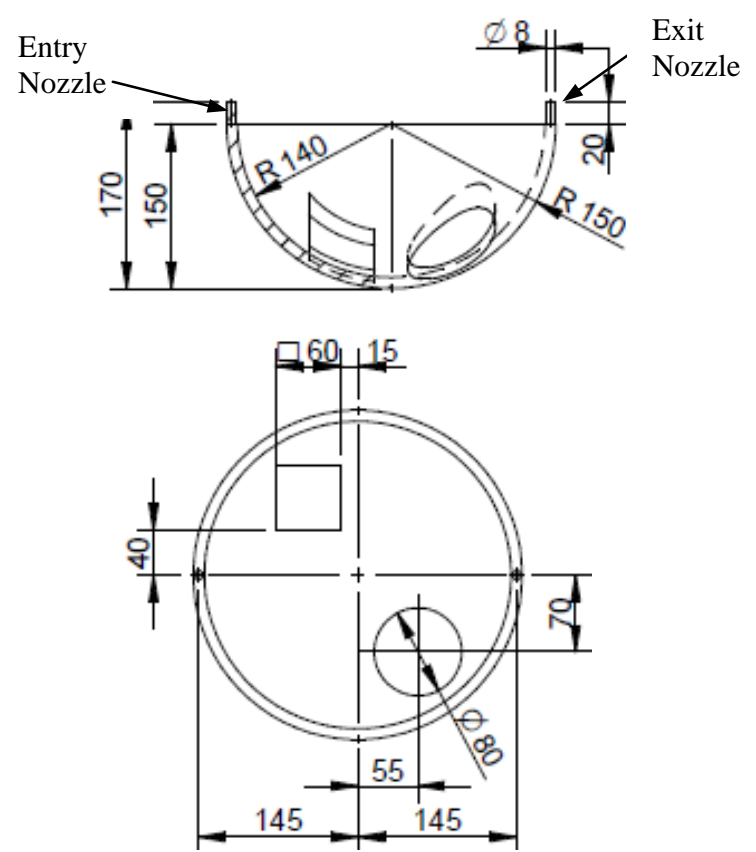

Figure 6. Perforated spherical calotte geometry: RTM process (in $\mathrm{mm}$ ).

The properties used in the simulations are: resin density $\rho=916 \mathrm{~kg} / \mathrm{m}^{3}$, resin viscosity $\mu=0.07115$ Pa.s and injection pressure $p=0.7 \times 10^{5} \mathrm{~Pa}$. The fibrous reinforcement has porosity $\varepsilon=0.88$ and permeability $K=3.89 \times 10^{-9} \mathrm{~m}^{2}$.

As shown in Figs. 5 and 6, resin is injected in the mold through an entry nozzle. An exit nozzle of air/resin mixture is placed on the opposite direction. It is worthy to mention that, for those geometries, tetrahedral meshes with characteristic length of $5 \mathrm{~mm}$ are employed. In this sense, a grid with 66144 and 61223 finite volumes are obtained for the spherical calotte and perforated spherical calotte cases, respectively. 
For the RTM simulations, the PAM-RTM software and FLUENT software were used. For the spherical calotte, the final injection time was $214 \mathrm{~s}$ for both numerical approaches. The qualitative behavior of the resin flow in the mold is illustrated in Fig. 7. It is noticed a similar behavior of the resin flow for the solutions obtained with PAM-RTM, Fig. 7(a), and with FLUENT, Fig. 7(b).


(b)
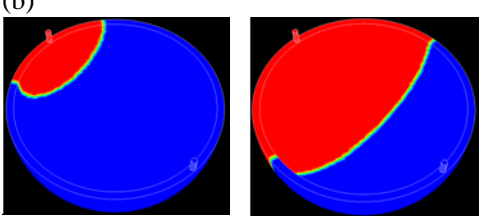

$\mathrm{t}=17.00 \mathrm{~s}$

$t=92.00 s$

$t=189.00 s$

Figure 7. Transient resin flow for the spherical calotte - RTM: (a) PAM-RTM, and (b) FLUENT.

For the perforated spherical calotte, the final injection time with PAM-RTM and FLUENT is $200 \mathrm{~s}$ and 203 s, respectively, a difference of nearly $2 \%$. The fluid movement around the obstacles can be noticed in Figs. 8(a) (PAM-RTM) and 8(b) (FLUENT).

In the perforated spherical calotte (Fig.8), when the resin reaches an obstacle, the flow surrounds the obstacle and continues its path almost uniformly, similar to the behavior for the spherical calotte mold (Fig. 7). This behavior is more evident for the circular obstacle. However, in general, the flow presents a similar characteristic to the rectilinear flow, in which the resin flow front tends to follow a straight line parallel to the lateral surfaces of the injection point, continuously advancing along the mold.

The comparison between Figs. 7 and 8 shows qualitatively that both solutions are similar. For the same time steps, the resin front line shows similar behavior, independently of the numerical approach used for the solution of the problem: PAM-RTM or FLUENT.

Numerical simulations of the LRTM process were carried out based on the computational model developed for the RTM process. In order to simulate the cases in the LRTM framework, a $10 \mathrm{~mm}$ thick edge is added to the mold perimeter of both geometries (without and with perforation) as shown in Figs. 9 and 10. (a)
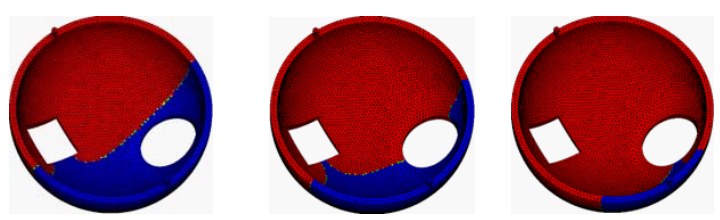

(b)

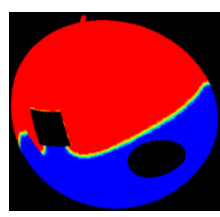

$t=100.00 s$

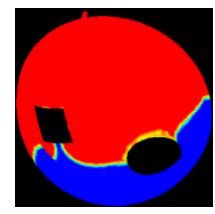

$t=120.00 s$

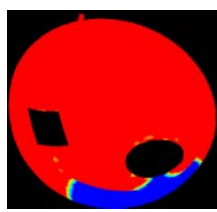

$\mathrm{t}=170.00 \mathrm{~s}$

Figure 8. Transient resin flow for the perforated spherical calotte - RTM using: (a) PAM-RTM and

(b) FLUENT.

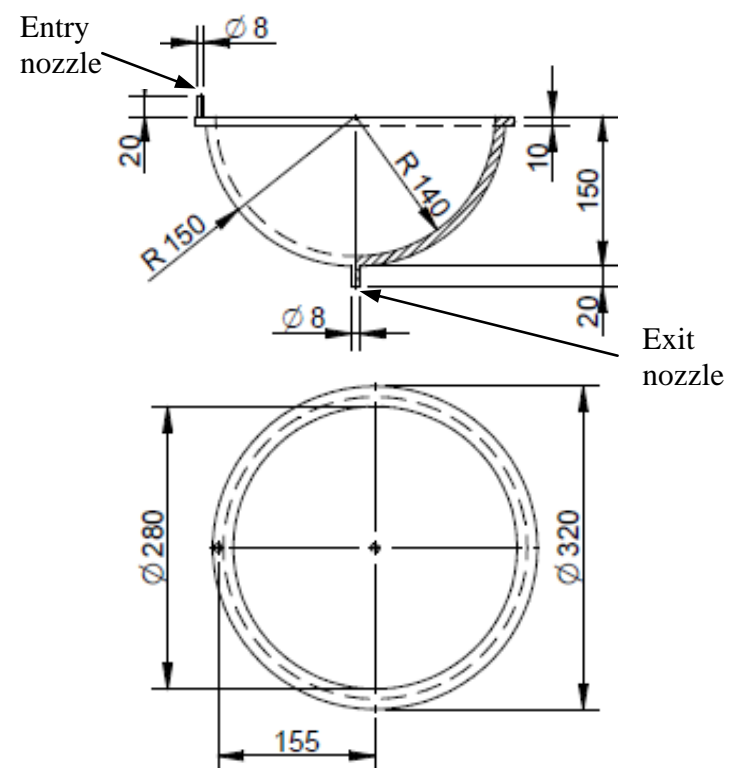

Figure 9. Spherical calotte geometry: LRTM Process (in $\mathrm{mm}$ ).

The insertion of this edge in the domain is the basis of the simulation of the LRTM process. In this case, resin is injected through the nozzle and goes on to the air/resin exit nozzle, which is located in the central region of the calotte. This new position is adopted once the injection is performed in a region without fiber medium. If the exit is placed in the board, the resin will not pass through the fibrous region. Figures 11 and 12 show the resin advance in three periods of time in the LRTM process for the spherical calotte and the perforated spherical calotte, respectively. The final injection time for the spherical calotte is $7 \mathrm{~s}$, which is only $3.3 \%$ of the injection time for the traditional RTM process. For the perforated spherical calotte with LRTM, the final injection time is $6.6 \mathrm{~s} \mathrm{(3.2 \%} \mathrm{of} \mathrm{the} \mathrm{total} \mathrm{time} \mathrm{for} \mathrm{the} \mathrm{RTM} \mathrm{process).}$ 




Figure 10. Perforated calotte geometry: LRTM process (in $\mathrm{mm}$ ).
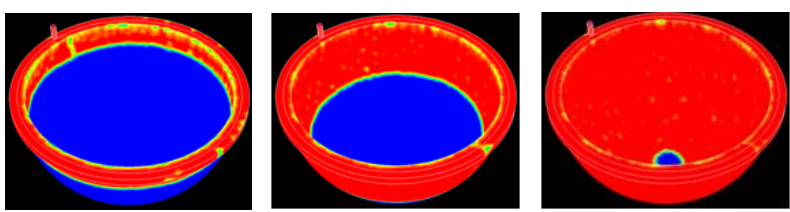

$\mathrm{t}=1.10 \mathrm{~s}$

$\mathrm{t}=2.60 \mathrm{~s}$

$t=6.80 s$

Figure 11. Transient resin flow for the spherical calotte - LRTM.

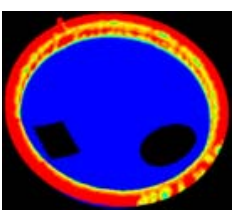

$\mathrm{t}=1.00 \mathrm{~s}$

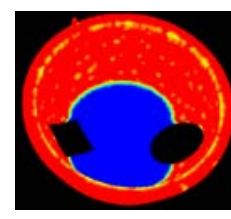

$\mathrm{t}=4.00 \mathrm{~s}$



$t=6.00 s$
Figure 12. Transient resin for the perforated spherical calotte - LRTM.

Analysis of the pressure distribution inside the mold was also carried out. For the perforated spherical calotte, for example, it is possible to observe that the pressure gradient reached for traditional RTM, Fig. 13(a), is significantly lower than that noticed for LRTM, Fig. 13(b). This is the main reason for the huge difference in filling time between these two processes (RTM and LRTM).

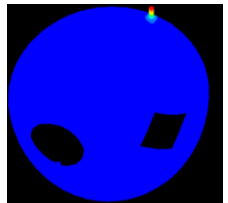

$\mathrm{t}=1.00 \mathrm{~s}$

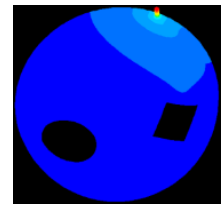

$\mathrm{t}=102.00 \mathrm{~s}$

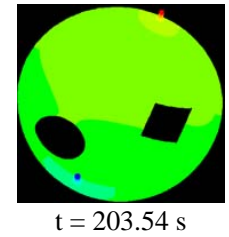

(a)
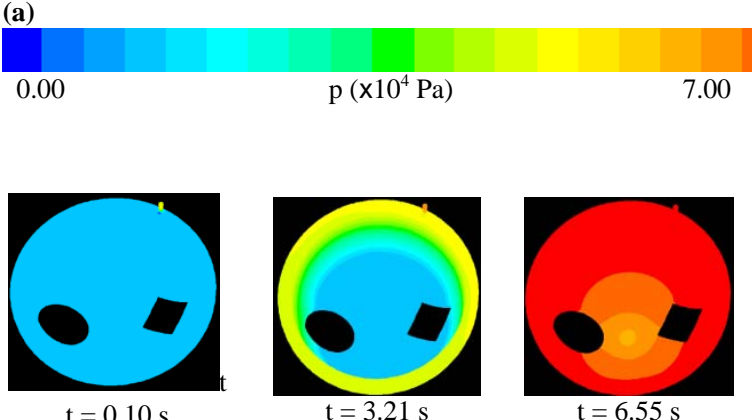

(b)

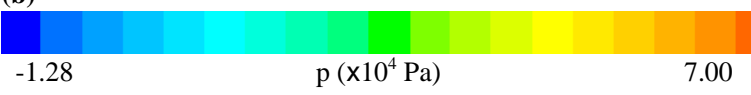

Figure 13. Pressure field for the perforated calotte: (a) RTM (b) LRTM.

Figures 13(a) and 13(b) also shows that the difference between maximum pressure, which is equal to the injection pressure, and the flow front pressure $\left(\Delta p=p_{0}-p_{f}\right)$ is the same in both processes. However, the distance between the points with pressure close to $\mathrm{p}_{0}$ and the flow front line is much smaller in the LRTM process. In addition, in the LRTM process, the pressure in the side edge is close to the injection pressure. Thus, as predicted by Darcy's Law, the resin flow velocity will be higher for the LRTM process than for the RTM process.

\section{CONCLUSION}

This work shows that it is possible to computationally model the RTM and LRTM processes by using the numerical approach employed in the FLUENT software. The FLUENT software allows the determination of the resin flow advance inside a computational domain comprised of regions with and without porous media, which is demanded for the simulation of the LRTM process.

It was possible to quantify the total resin injection time in the mold for the LRTM and RTM processes, and the time required for mold filling is significantly higher for traditional RTM in comparison with the LRTM process. The numerical results showed that this is basically related to the pressure gradient, which is much higher for LRTM than for RTM.

It is also important to emphasize the importance of this work, taking into consideration that there are several numerical models and solution methodologies 
to determine the resin advance in the RTM process. However, there is virtually no work in literature for the LRTM process.

\section{ACKNOWLEDGEMENTS}

The authors thank CNPq and FAPERGS for the support.

\section{REFERENCES}

Amico, S. C., 2005, Novo Processo de Fabricação de Compósitos para Indústria, Revista Ciência Hoje, Vol. 219 pp. 55-55. (in Portuguese)

Hirt, C. W., and Nichols, B. D., 1981, Volume of Fluid (VOF) Method for Dynamics of Free Boundaries, Journal of Computational Physics, Vol. 39, pp. 201-225.

Isoldi, L. A., Oliveira, C. P., Rocha, L. A. O., Souza, J. A., and Amico, S. C., 2012, ThreeDimensional Numerical Modeling of RTM and LRTM Processes, Journal of the Brazilian Society of Mechanical Sciences and Engineering, Vol. 34, No. 2, pp. 105-110.

Jinlian, H., Liu, Y., and Xueming, S., 2004, Study on Void Formation in Multilayer Woven Fabrics, Composites Part A, Vol. 35, pp. 595-603.

Oliveira, C. P., 2010, Modelagem Numérica do Transporte de Resinas em Meio Poroso Aplicado ao Processo de RTM, Master Thesis, Universidade Federal do Rio Grande, Rio Grande, RS. (in Portuguese)

Porto, J. Da S., Teixeira, F. P., Letzow, M., Amico, S. C., Santos, E. D. Dos, Souza, J. A., and Isoldi, L. A., 2011, Modelagem Computacional do Processo de Light Resin Transfer Molding (LRTM), in: Iberan Latin American Congress on Computational Methods in Engineering, Universidade Federal de Ouro Preto, pp. 1-18

Ribeiro, G. G., Souza, J. A., Rocha, L. A. O., and Amico, S. C., 2007, Utilização do Aplicativo "FLUENT" na Modelagem Numérica do Processo RTM, in: Congresso Brasileiro de Carbono. (in Portuguese)

Schmidt, T. M., Goss, T. M., Amico, S. C., and Lekakou, C., 2009, Permeability of Hybrid Reinforcements and Mechanical Properties of Their Composites Molded by Resin Transfer Molding, Journal of Reinforced Plastics and Composites, Vol. 28, pp. 2839-2850.

Shin, K. S., Song, Y. S., and Youn, J. R., 2006, Radial Flow Advancement in Multi-Layered Preform for resin Transfer Molding, Rheology Journal, Vol. 18, No. 4, pp. 217-224.

Shojaei, A., 2006, A Numerical Study of Filling Process Through Multilayer Performs in Resin Injection/Compression Molding, Composites Science and Technology, Vol. 66, pp. 1546-1557.

Srinivasan, V., Salazar, A. J., and Saito K., 2011, Modeling the Disitengration of Modulated
Liquid Jets Using Volume-of-Fluid (VOF) Methodology, Applied Mathematical Modeling, pp. 3710-3730

Villas, F. B., 2006, Desenvolvimento de uma Ferramenta de CAD Aplicada ao Projeto de Hélices para Veículos Aquáticos Não Tripulados, Master Thesis, Escola Politécnica da Universidade de São Paulo, São Paulo, SP. (in Portuguese)

Received: September 30, 2012

Revised: October 30, 2012

Accepted: November 30, 2012 